\title{
Desvenlafaxine in the treatment of major depressive disorder
}

\author{
Maria Teresa C Lourenco' \\ Sidney H Kennedy ${ }^{1,2}$ \\ 'Department of Psychiatry, \\ University Health Network, Toronto; \\ ${ }^{2}$ Department of Psychiatry, University \\ of Toronto, Toronto, Canada
}

\begin{abstract}
Major depressive disorder (MDD) is among the most incapacitating conditions in the world. The emergence of the selective serotonin reuptake inhibitor (SSRI) and serotonin norepinephrine reuptake inhibitors (SNRI) antidepressants has improved the treatment of MDD. Desvenlafaxine succinate (DVS) is the succinate salt of the isolated major active metabolite of venlafaxine, $O$-desmethylvenlafaxine: it is the third SNRI to become available in the United States, and was approved in 2008 by the US Food and Drug Administration (FDA) for the treatment of MDD. Early investigations showed therapeutic efficacy for doses between 50 and $400 \mathrm{mg}$ /day; however in doses above $100 \mathrm{mg}$ /day there were incremental increases in side effects. Nausea was the most frequent adverse effect. Hence the recommended dosing for DVS is in the 50 to $100 \mathrm{mg}$ range. Desvenlafaxine is excreted in urine, it is minimally metabolized via the CYP450 pathway, and is a weak inhibitor of CYP2D6. A reduced risk for pharmacokinetic drug interactions is a potential advantage over other SNRI. Further head-to-head trials involving comparisons of DVS in the 50 to $100 \mathrm{mg}$ dose range with currently available SSRI and SNRI antidepressants are required. Evidence for relapse prevention is available in the 200 to $400 \mathrm{mg}$ dose range, but this needs to be demonstrated in the 50 to $100 \mathrm{mg}$ dose range, as well as health economic measures and quality of life evaluations.
\end{abstract}

Keywords: desvenlafaxine, $O$-desmethylvenlafaxine, Pristiq ${ }^{\circledR}$, SNRIs, MDD

\section{Introduction}

Major depressive disorder (MDD) is the single most frequent psychiatric disorder in the USA, with an estimated lifetime prevalence of $16.6 \%$ and is among the most incapacitating conditions in the world. ${ }^{1}$ According to the Global Burden of Disease Study, using disability adjusted life-years (DALYs) as a measure of lost years of healthy life, depression was ranked fourth in $2000^{2}$ and is estimated to rank first in $2030 .^{3}$ Depression was the foremost cause of years lived with disability for both men and women in $2001 .^{4}$ In Canada, the lifetime prevalence of MDD was $11.2 \%{ }^{5}$

Depression is often comorbid with chronic medical diseases and can worsen associated health outcomes. The prevalence of depression in a large population based health outcomes study was estimated for those respondents who suffered from chronic physical diseases (angina, arthritis, asthma and diabetes). ${ }^{6}$ Comorbid depression was identified in $9 \%$ to $23 \%$ of individuals with one or more chronic physical disease, significantly higher than the likelihood of having depression in the absence of a chronic physical disease $(\mathrm{p}<0.0001)$. These findings emphasize the importance of providing safe and effective treatment to people with a diagnosis of MDD, including those with comorbid medical disorders.

Despite significant advances in the treatment of MDD, between $30 \%$ and $50 \%$ of depressed patients have an inadequate response to the first antidepressant therapy. MDD often recurs, and an incomplete recovery from an index episode has been shown to increase the risk of chronicity and recurrence. ${ }^{7}$ The emergence of the selective serotonin 
reuptake inhibitors (SSRI) and serotonin norepinephrine reuptake inhibitors (SNRI) antidepressants has improved the treatment of MDD. Nevertheless, data from the Sequenced Treatment Alternatives to Relieve Depression (STAR*D) trial indicate that approximately $70 \%$ of the patients with MDD do not achieve remission following adequate treatment with a single SSRI, ${ }^{8}$ and the incremental likelihood of achieving remission progressively diminishes over three further interventions. ${ }^{9}$

\section{The serotonin and norepinephrine reuptake inhibitors}

The first dual reuptake SNRI antidepressant was the immediaterelease form of venlafaxine, launched in the United States in 1994. The extended-release (ER) formulation, venlafaxine XR, followed in 1997, resulting in better tolerability and comparable or superior efficacy. As a follow up to the initial report of clinically meaningful differences in rates of remission between venlafaxine and SSRIs, ${ }^{10}$ Nemeroff and colleagues expanded the meta-analysis to include all identified comparative trials involving venlafaxine and an SSRI (Comprehensive Analysis of Remission - COMPARE). ${ }^{11}$ They reported that "venlafaxine therapy is statistically superior to SSRIs as a class, but only to fluoxetine individually," and noted that attrition rates due to adverse events were higher with venlafaxine than with SSRIs. Underscoring the complexities of meta analytic approaches, Weinmann et al ${ }^{12}$ included 17 venlafaxine versus SSRI studies, and did not find evidence that venlafaxine has superior efficacy or a better side effect profile than SSRI. There is no evidence that venlafaxine is superior to escitalopram. ${ }^{13,14}$

Ten years after the launch of venlafaxine, duloxetine was introduced in the USA (2004), and has become widely available throughout the world. In a meta-analysis of 6 randomized studies, duloxetine had superior efficacy than both fluoxetine
$20 \mathrm{mg} /$ day and paroxetine $20 \mathrm{mg} /$ day in the treatment of patients with moderate to severe depression. ${ }^{15}$ In comparison to escitalopram, duloxetine has not displayed any clinical advantage. ${ }^{16,17}$ Although milnacipram, an SNRI with preferential inhibitory effects on the norepinephrine transporter, is available as an antidepressant across many European countries and in Japan, it has not been licensed in North America, and is currently being evaluated for the treatment of fibromyalgia.

\section{Desvenlafaxine succinate}

Desvenlafaxine succinate (DVS) is the third SNRI to become available in the United States. It is indicated for the treatment of MDD although it has also been investigated as a treatment for vasomotor symptoms associated with menopause ${ }^{18,19,20}$ and for the treatment of fibromyalgia. ${ }^{21}$

\section{Pharmacodynamics and pharmacokinetics}

DVS is the succinate salt of the isolated major active metabolite of venlafaxine, "O-desmethylvenlafaxine" (Figure 1). Venlafaxine is metabolized in the liver through the cytochrome P450 system into three metabolites: $O$-desmethylvenlafaxine, $\mathrm{N}$-desmethylvenlafaxine, and $\mathrm{N}, \mathrm{O}$-desmethylvenlafaxine.

DVS displays competitive binding interactions at both the human serotonin (5-HT) transporter (hSERT; $\mathrm{K}_{\mathrm{i}}=40 \pm$ $1.6 \mathrm{nM}$ ) and the human norepinephrine (NE) transporter (hNET; $\mathrm{K}_{\mathrm{i}}=558 \pm 121.6 \mathrm{nM}$ ), with only weak affinity for the human dopamine (DA) transporter (hDAT; $\left.\mathrm{K}_{\mathrm{i}}=25 \mu \mathrm{M}\right)$. In vitro functional assays indicate that DVS is approximately 10-fold more potent as an inhibitor of 5-HT uptake than NE uptake. $^{22-24}$ Affinity for muscarinic, cholinergic, histamine $\mathrm{H}_{1}-$, and alpha ${ }_{1}$ adrenergic receptors is very low. ${ }^{22,23}$

DVS increases extracellular levels of both NE and 5-HT without increasing DA levels in the hypothalamus of ovariectomized rats. ${ }^{18}$ In male rats, DVS is brain-penetrable and increases neurotransmitters in the hypothalamus, a region of

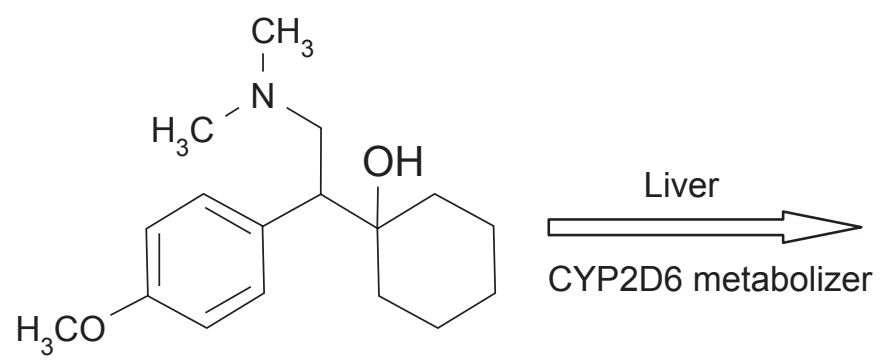

Venlafaxine

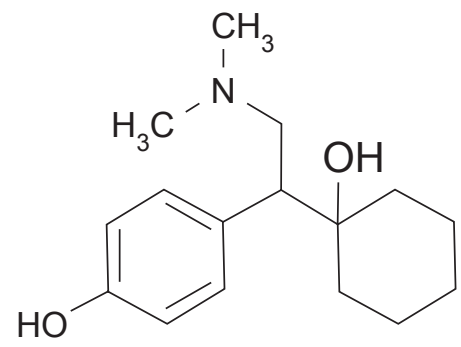

Desvenlafaxine

Figure I Desvenlafaxine succinate molecule. 
the brain involved in pain sensation as well as temperature and mood regulation. ${ }^{22}$

DVS is designated $R S$-4-[2-dimethylamino-1(hydrox ycyclohexyl)ethyl]phenol, with an empirical formula of $\mathrm{C}_{16} \mathrm{H}_{25} \mathrm{NO}_{2}$ (free base) and $\mathrm{C}_{16} \mathrm{H}_{25} \mathrm{NO}_{2} \cdot \mathrm{C}_{4} \mathrm{H}_{6} \mathrm{O}_{4} \cdot \mathrm{H}_{2} \mathrm{O}$ (succinatemonohydrate) and a molecular weight of 399.48. ${ }^{25}$

It is formulated as a sustained release tablet $(50 \mathrm{mg}$ or $100 \mathrm{mg}$ ) for once-a-day oral administration. Single-dose studies indicate linear and dose-proportional pharmacokinetics in a dose range between $100 \mathrm{mg} /$ day to $600 \mathrm{mg}$ /day. The mean terminal half-life $\left(\mathrm{t}_{1 / 2}\right)$ is approximately 11 hours, ${ }^{26}$ with maximum plasma concentration $\left(\mathrm{T}_{\max }\right)$ within 7.5 hours of oral administration. With once-daily dosing, steady-state plasma concentrations are achieved within approximately 4 to 5 days, and multiple-dose accumulation of DVS is linear and predictable. The absolute bioavailability of the oral formulation is $80 \%$, and absorption is minimally affected by food..$^{27,28}$

DVS sustained release was considered safe in healthy volunteers up to a single dose of $750 \mathrm{mg}^{27}$ and was well tolerated in multiple doses up to $450 \mathrm{mg} .{ }^{28}$ The plasma protein binding of DVS is low (30\%) and is independent of drug concentration. This is likely to result in high brain concentration of the drug. It is also a weak inhibitor of CYP2D6. To examine the clinical implications, the effects of DVS $100 \mathrm{mg}$ and duloxetine $30 \mathrm{mg}$ bid on plasma levels of desipramine were compared in healthy subjects in a randomized, open label, crossover study. ${ }^{29}$ In comparison to desipramine alone, co-administration of duloxetine resulted in increases in AUC and $\mathrm{C}_{\text {max }}$ of desipramine (122\% and 63\% respectively). These were significantly greater than the increases observed with DVS co-administration ( $22 \%$ and $19 \%$, respectively), suggesting that DVS is not a clinically significant inhibitor of CYP2D6 activity.

DVS is primarily metabolized by conjugation and, to a minor extent, through CYP3A4 mediated oxidative metabolism. Approximately $45 \%$ is excreted unchanged in urine at 72 hours after oral ingestion, while $20 \%$ of the administered dose is excreted as the glucuronide metabolite and $<5 \%$ as the oxidative metabolite ( $N, O$-didesmethylvenlafaxine) in urine. ${ }^{25}$

\section{Effect of hepatic and renal impairment}

DVS $100 \mathrm{mg}$ has been examined in a small sample of hepatically impaired subjects and matched healthy adults. There was a lower clearance and longer $t_{1 / 2}$ only in subjects with moderate to severe hepatic impairment. ${ }^{30}$ Thus, there does not appear to be any need to reduce the starting dose for patients with mild hepatic impairment.
Since DVS is almost entirely excreted in urine, patients with renal impairment present a greater clinical concern. The disposition of DVS after administration of $100 \mathrm{mg}$ was studied in subjects with mild $(n=9)$, moderate $(n=8)$, severe $(n=7)$ and end stage renal disease $(n=9)$, and in healthy, age-matched control subjects $(n=8)$. Elimination was significantly correlated with creatinine clearance. Increases in AUC compared to the control group were proportional to the degree of renal impairment: mild $42 \%$; moderate $46 \%$; severe $108 \%$ and end stage $116 \%$. The mean terminal half-life $\left(\mathrm{t}_{1 / 2}\right)$ was prolonged. Dosage adjustment to alternate day dosing is recommended in patients with significant impairment of renal function. ${ }^{25}$

\section{Efficacy in clinical trials}

As of October 2008, 6 published DVS efficacy trials in MDD were identified. ${ }^{31-36}$ Several published abstracts were also reviewed: including a flexible dose trial of DVS 200 to $400 \mathrm{mg},{ }^{37}$ a trial comparing DVS 50 and $100 \mathrm{mg}$ to placebo with a duloxetine reference $\mathrm{arm},{ }^{8}$ as well as two unpublished pooled analyses, the first involving 7 short-term trials with DVS doses between 100 and $400 \mathrm{mg}^{39}$ and the second from 2 trials with DVS at 50 and $100 \mathrm{mg} .{ }^{40}$ Other studies of DVS as a treatment for vasomotor symptoms of menopause and pain were not reviewed. No published trials for generalized anxiety disorder or other anxiety disorders were located.

\section{Clinical trial design}

Five of the published studies for DVS in the treatment of MDD were placebo controlled RCTs, and one was a pooled analysis from 2 otherwise unpublished clinical trials.

The initial dose finding trials examined doses of 100 , 200 or $400 \mathrm{mg} / \mathrm{day},{ }^{31-33}$ while subsequent trials evaluated daily doses of 50 and $100 \mathrm{mg} .{ }^{34,35}$ Of 5 individual published clinical trials, 4 had a similar fixed-dose design while 1 was a flexible dose study.

The inclusion criteria were generally similar and involved outpatients with a primary diagnosis of MDD, single or recurrent episodes, without psychotic features, between 18 and 75 years of age, although two trials ${ }^{34,35}$ did not define an upper age limit. Depressive symptoms had to have been present for at least 30 days before the screening visit, and a minimum score of 20 on the 17-item Hamilton Rating Scale for Depression $\left(\mathrm{HAM}-\mathrm{D}_{17}\right.$ ) was required.

Usual exclusion criteria were applied, including a diagnosis of bipolar Ddisorder. Participants were also excluded if they had previously received treatment with DVS or venlafaxine within 90 days of the baseline. Three of the trials, in 
which the doses of DVS ranged from 100 to $400 \mathrm{mg} /$ day, ${ }^{31-33}$ excluded depressed patients with high levels of anxiety (defined as a Covi Anxiety Scale total score greater than 3 on any single item, a total score greater than 9, or a score greater than the Raskin Depression Scale total score). The length of the treatment for all the studies was 8 weeks, followed by one or 2 weeks of tapering, and a follow up visit 7 days after the last dose. An option to enroll in a long-term open label extension study was offered to the patients who participated in three of these studies. ${ }^{31-33}$

\section{DVS trials in doses of $100 \mathrm{mg} /$ day and higher}

In all trials, the 17-item version of the Hamilton Rating Scale for Depression $\left(H A M-D_{17}\right)^{41}$ was the primary efficacy measure and the Clinical Global Impressions-Improvement scale (CGI-I) was a secondary efficacy measure. Other secondary measures included the Montgomery-Asberg Depression Rating Scale (MADRS), Clinical Global Impressions-Severity scale (CGI-S), and Visual Analog Scale-Pain Intensity (VAS-PI). In four of the trials, ${ }^{32-35}$ the Covi Anxiety Scale, Sheehan Disability Scale (SDS) and World Health Organization 5-item Well Being Index (WHO-5) were also secondary outcome measures. One study ${ }^{35}$ also included a subscale of core depressive symptoms, the HAM-D $6{ }^{42}$ The primary end point for all efficacy measures was the "final on therapy" (FOT) evaluation of the intent-to-treat (ITT) population, using the last-observation-carried-forward (LOCF) method to account for missing data.

In the first trial by DeMartinis et $\mathrm{al}^{32} 480$ subjects were randomized to receive DVS 100, 200 or $400 \mathrm{mg} /$ day, or placebo. The doses were up titrated over 8 days. During the taper phase, doses were reduced to the next lower dose at weekly intervals. This study reported a significant drugplacebo difference in adjusted mean change from baseline in the HAM $D_{17}$ for DVS $100 \mathrm{mg} /$ day $(-10.60 ; \mathrm{p}=0.0038)$ and $400 \mathrm{mg} /$ day $(-10.74 ; \mathrm{p}=0.0023)$ compared to placebo $(-7.65)$, but not for DVS $200 \mathrm{mg} /$ day $(-9.63$; $\mathrm{p}=0.0764)$. Among the secondary end points, there was a significant difference in favor of DVS at both doses on CGI-I. Adjusted odds ratio for response rates compared to placebo, were 2.16 (95\% CI $=1.25-3.73)$ for $100 \mathrm{mg}$ DVS $(\mathrm{p}=0.0060), 1.60$ (95\% CI $=0.93-2.76)$ for $200 \mathrm{mg}$ DVS $(\mathrm{p}=0.089)$, and 1.92 (95\% CI = 1.11-3.32) for $400 \mathrm{mg}$ DVS ( $\mathrm{p}=0.020$.). These differences correspond to response rates of $52 \%$ for DVS $100 \mathrm{mg}$ and 48\% for DVS $400 \mathrm{mg}$.

For remission, the adjusted odds ratios in relation to placebo were: $1.87(95 \% \mathrm{CI}=0.99-3.52)$ for DVS $100 \mathrm{mg}$ $(\mathrm{p}=0.053), 1.73(95 \% \mathrm{CI}=0.92-3.26)$ for $200 \mathrm{mg} \mathrm{DVS}$ $(\mathrm{p}=0.088)$ and $2.20(95 \% \mathrm{CI}=1.17-4.14)$ for $400 \mathrm{mg}$ DVS ( $p=0.014)$. This corresponds in the DVS $400 \mathrm{mg}$ group to a $33 \%$ remission rate. Participants taking DVS $100 \mathrm{mg}$ also showed significantly greater improvement in the overall pain measure compared to the placebo group.

In the second trial by by Septien-Velez and colleagues, ${ }^{31}$ 375 patients were randomized to receive DVS 200 or $400 \mathrm{mg} /$ day, or placebo. Patients assigned to the $400 \mathrm{mg} /$ day dose, had a 1-week escalation period. There was a significantly greater reduction in HAM-D ${ }_{17}$ from baseline for both DVS $200 \mathrm{mg} /$ day $(-12.6 \pm 0.75 ; \mathrm{p}=0.002)$ and DVS $400 \mathrm{mg} /$ day $(-12.1 \pm 0.74 ; \mathrm{p}=0.008)$ compared with placebo $(-9.3 \pm$ $0.74)$ on the final evaluation. There were also significant differences in mean CGI-I scores versus placebo for both doses of DVS. Both DVS $200 \mathrm{mg} /$ day $(\mathrm{p}<0.001)$ and $400 \mathrm{mg} /$ day $(\mathrm{p}=0.005)$ yielded significantly higher rates of response $(60 \%$ and $57 \%$ respectively compared to $39 \%$ on placebo) although remission was significant only for DVS $200 \mathrm{mg} /$ day ( $38 \%$ vs $22 \%, \mathrm{p}=0.017$ ).

In a third and negative trial, ${ }^{33} 247$ patients were randomized to receive DVS $200 \mathrm{mg}$ /day (that could be lowered to $100 \mathrm{mg} /$ day if indicated) or placebo. During the discontinuation phase, patients on DVS $200 \mathrm{mg}$ received 1 week at $100 \mathrm{mg}$. The adjusted mean change from baseline on HAM-D was 14.1 for DVS (100-200 mg/day) versus 15.1 for placebo (not significant). Similarly the CGI-I scores (2.5 for DVS group and 2.7 for placebo) were not statistically significantly different, although other secondary measures including MADRS $(p=0.047)$ and VAS-PI overall pain $(p=0.008)$ were statistically different from placebo. Neither were there statistically significant differences between DVS and placebo rates of response or remission.

A pooled analysis presented results from 2 otherwise unpublished double blind, venlafaxine ER-referenced flexible dose RCTs. ${ }^{36}$ Each was a negative trial for DVS, but assay sensitivity was confirmed in the venlafaxine group. Data on DVS from both studies were pooled post hoc, and yielded positive results. The treatment groups were: DVS (target dose $200 \mathrm{mg}$ /day, with option to increase to $400 \mathrm{mg}$ /day after day 28), venlafaxine ER $75 \mathrm{mg} /$ day to $150 \mathrm{mg} /$ day (Europe) or venlafaxine ER $150 \mathrm{mg} /$ day to $225 \mathrm{mg}$ /day (USA) or placebo. The following minimum scores were required at the screening and baseline visits: $H A M-D_{17} \geq 22$, score $\geq 2$ on item 1 , CGI-S $\geq 4$ (moderately ill) and a greater score on the Raskin Depression Scale than the Covi Anxiety Scale. Patients with comorbid Generalized Anxiety Disorder, Panic Disorder, or Social Anxiety Disorder were allowed to participate if MDD was the 
primary diagnosis. The length of the treatment was 8 weeks, plus a taper period based on the final dose for the three arms.

All efficacy analyses included the ITT population (713 subjects). Data from the venlafaxine ER groups were not pooled due to the difference in doses in the two trials. The longitudinal changes from baseline on pooled data for the primary efficacy measure and the secondary measures were analyzed using a mixed-effect model for repeated measures (MMRM). A logistic regression model was used for binary outcome variables: response and remission measured by the HAM-D $_{17}$ and CGI-I.

The change on HAM-D ${ }_{17}$ total score from baseline was greater for DVS than for placebo, with a magnitude of effect $=-2.34 ;(p<0.001)$. Statistically significant differences in CGI-I scores for DVS versus placebo were observed (2.0 versus 2.3; $\mathrm{p}<0.001$ ); both venlafaxine ER groups were significantly different from placebo at week 8 for HAM-D total score $(\mathrm{p}=0.001$ and $\mathrm{p}<0.001)$ and CGI-I scores $(\mathrm{p}=0.003$ and $\mathrm{p}<0.001)$.

The differences in HAM-D ${ }_{17}$ response and remission rates for DVS compared to placebo were not statistically significant. For both venlafaxine ER groups, response rates versus placebo were significant, although remission rate was significant only for venlafaxine ER 150 to $225 \mathrm{mg} /$ day ( $\mathrm{p}=0.003$ ). CGI-I response rates were not statistically significant for DVS versus placebo, but were statistically significant for both venlafaxine ER groups (75-150 $\mathrm{mg}$ and 150-225 mg).

The treatment effect of DVS (dose range 200-400 mg) observed using MMRN analysis was 2.3 points on the HAM-D ${ }_{17}$, and it was in line with that observed for venlafaxine ER 75 to $150 \mathrm{mg} /$ day (2.4) and venlafaxine ER 150 to $225 \mathrm{mg} /$ day (2.7) in the individual studies. Desvenlafaxine was considered efficacious to treat MDD in the pooled analysis of the data using MMRM models.

\section{DVS trials in doses of $50 \mathrm{mg}$ and $100 \mathrm{mg}$}

In both published trials, ${ }^{34,35}$ eligible patients were randomly assigned to receive DVS 50 or $100 \mathrm{mg}$ /day or placebo, and results were inconsistent. In the first low-dose trial, ${ }^{34}$ the adjusted mean change from baseline in HAM-D $\mathrm{D}_{17}$ total score was significantly greater for both DVS $50 \mathrm{mg} /$ day $(-13.2$; $\mathrm{p}=0.002)$ and DVS $100 \mathrm{mg} /$ day $(-13.7 ; \mathrm{p}<0.001)$ versus placebo (-10.7). Significant differences were observed starting at week 4 for DVS $100 \mathrm{mg}$ /day and at week 6 for DVS $50 \mathrm{mg} /$ day. CGI-I scores in the DVS $50 \mathrm{mg} /$ day and DVS $100 \mathrm{mg} /$ day groups were significantly lower than placebo at end point ( $p=0.003$ and $p<0.001$, respectively). Rates of response were significantly greater for DVS $50 \mathrm{mg} /$ day $(65 \% ; \mathrm{p}=0.005)$ and $100 \mathrm{mg} /$ day $(63 \% ; \mathrm{p}=0.018)$ versus placebo $(50 \%)$, although remission rates were significantly different only for DVS $100 \mathrm{mg}$ /day (45\% DVS versus 29\% placebo, $\mathrm{p}=0.003$ ), but not for DVS $50 \mathrm{mg}$ ( $37 \%$ versus 29\%; $\mathrm{p}=0.100)$. Based on differences in response and remission rates, these results would translate into number needed to treat (NNT) values of 6 to 7 patients to achieve response at 50 and $100 \mathrm{mg}$ doses, and NNT $=6$ for remission on DVS $100 \mathrm{mg}$.

In the second study ${ }^{35}$ the HAM-D ${ }_{17}$ adjusted mean change from baseline was significantly greater for DVS $50 \mathrm{mg} /$ day compared to placebo $(1.9, \mathrm{p}=0.018)$, but not for DVS $100 \mathrm{mg} /$ day $(1.5, \mathrm{p}=0.065)$, although significant differences for DVS $100 \mathrm{mg} /$ day at 8 weeks versus placebo were identified using two other methods of statistical analysis.

The differences on the HAM-D ${ }_{6}$ sub scale were significant for DVS $50 \mathrm{mg}$ (difference in adjusted means: 1.3; $\mathrm{p}=0.010$ ) and DVS $100 \mathrm{mg} /$ day (difference in adjusted means: 1.0; $\mathrm{p}=0.038)$. Significant differences were observed for DVS $50 \mathrm{mg} /$ day $(2.7, \mathrm{p}=0.022)$ in the adjusted mean score for MADRS, WHO-5 and SDS total score (WHO-5: $\mathrm{p}=0.020$, SDS: $p=0.012$ ) but not for DVS $100 \mathrm{mg} /$ day. There were no statistically significant differences from placebo in either DVS $50 \mathrm{mg} /$ day or $100 \mathrm{mg} /$ day groups for CGI-I, CGI-S or Covi Anxiety Scale scores.

Using logistic regression analysis, response rates for HAM-D ${ }_{17}$, MADRS, and CGI-I did not differ statistically among groups, although remission rates were greater in the DVS $50 \mathrm{mg}$ /day group compared to placebo (logistic regression analysis, 34\% versus 24\%; $\mathrm{p}=0.027$ ) (Figures 2 and 3).

Additional preliminary data have been presented at scientific meetings. Liebowitz, Montgomery, Boyer et al $(2007)^{40}$ reported that once-daily DVS 50 and $100 \mathrm{mg} /$ day demonstrated significantly greater improvements at week 8 compared with placebo on measures of efficacy in twoplacebo controlled trials. A pooled analysis from 7 short-term placebo-controlled trials reported that DVS was an effective treatment for MDD, and no additional benefit was observed with DVS doses above $100 \mathrm{mg} /$ day. ${ }^{39}$ Data from an unpublished duloxetine referenced short-term study on fixed doses of DVS $50 \mathrm{mg} /$ day and $100 \mathrm{mg} /$ day to treat MDD, failed to confirm superiority for DVS $50 \mathrm{mg}$ /day compared to placebo, but there were statistically significant differences for DVS $100 \mathrm{mg}$ and duloxetine $60 \mathrm{mg}$ compared to placebo. ${ }^{38}$

\section{Special populations}

There are ongoing clinical trials in several sub populations of MDD patients. Two studies involve children and adolescents. ${ }^{21}$ A long-term safety and tolerability open trial 


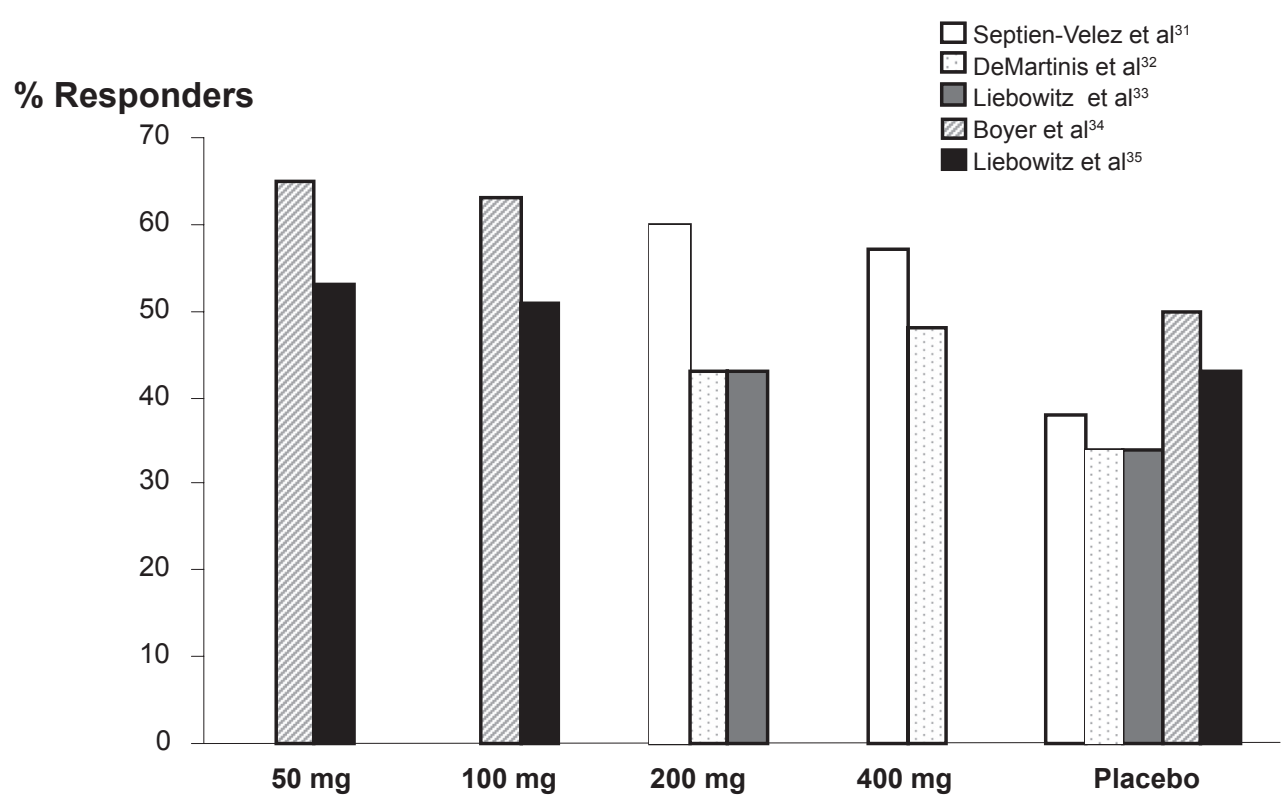

Figure 2 Desvenlafaxine succinate response rates by dose across studies.

of DVS (flexible doses: 100-200 mg/day) in elderly MDD patients has been completed, and results show that the adverse events are similar in type and frequency to those observed in adults. ${ }^{21}$ DVS has also been compared to escitalopram in postmenopausal women. ${ }^{21}$ There are no data to support the use of DVS during pregnancy and lactation.

\section{Relapse prevention and maintenance trials} In a 6-month relapse prevention trial, the DVS group (dose range $200-400 \mathrm{mg}$ /day) had significantly fewer relapses (24\%) compared to the placebo group $(42 \%){ }^{43}$ There are no reports of relapse prevention in the 50 to $100 \mathrm{mg}$ /day dose range of DVS.

Results from an open label, 12-month, flexible dose trial of DVS (mean $>300 \mathrm{mg}$ /day) showed a steady decrease in HAM-D ${ }_{17}$ total score from baseline of approximately nine points, and statistically significant improvements from baseline in disability measures assessed by the SDS. ${ }^{44}$

\section{Safety and tolerability}

The incidence of treatment-emergent adverse events (TEAEs) in the published trials, defined as adverse events reported by

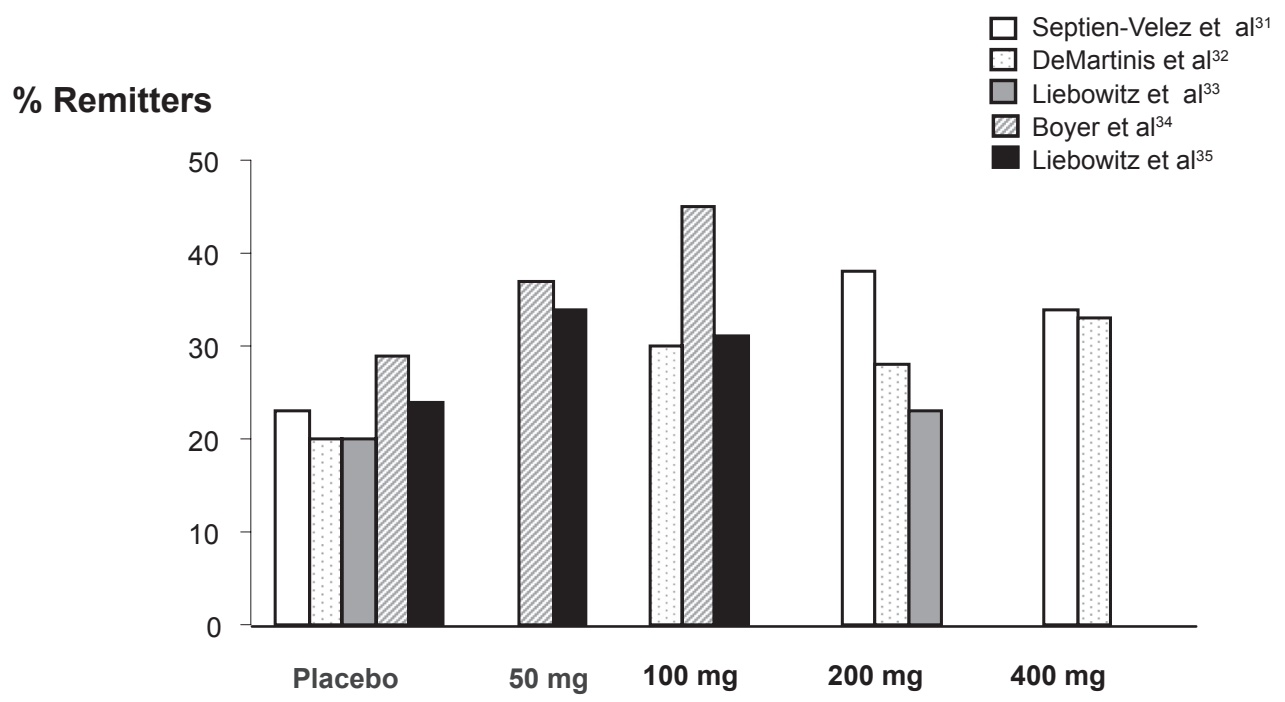

Figure 3 Desvenlafaxine succinate remission rates by dose across studies. 
at least $5 \%$ of participants in the treatment group occurring at least twice as frequently as on placebo, revealed a linear relationship between TEAEs and DVS dose: DVS $50 \mathrm{mg} /$ day$78 \%$ to $84 \%$; DVS $100 \mathrm{mg} /$ day- $76 \%$ to $90 \%$; DVS 200 to $400 \mathrm{mg} /$ day $-85 \%$ to $93 \%$. The placebo reported frequencies of TEAEs ranged from $62 \%$ to $84 \%$. In most cases the TEAEs were mild to moderate.

Nausea was the most frequently reported adverse event: $17 \%$ to $27 \%$ of patients receiving $50 \mathrm{mg} /$ day, ${ }^{34,35}$ and $16 \%$, $30 \%$ and $35 \%$ respectively in each of the $100 \mathrm{mg}$ studies $32,34,35$ reported nausea, although in all cases, rates declined markedly after 1 to 2 weeks. For patients taking DVS $200 \mathrm{mg}$ /day or $400 \mathrm{mg} / \mathrm{day}$, nausea was reported with a frequency ranging from $30 \%$ to $46 \% .^{31,32,33}$ Nausea was higher in the DVS (200 and $400 \mathrm{mg} /$ day) groups (38\%) compared to both venlafaxine groups (75-150 mg/day: 21\%; 150-225 mg/day: 29\%). ${ }^{36}$

The most frequently reported TEAEs other than nausea were: insomnia, somnolence, dry mouth, dizziness, sweating, nervousness, anorexia, constipation, asthenia, and sexual dysfunction (Table 1).

The overall discontinuation rate was comparable across studies and was approximately $23 \%$ : DVS groups ranged from $22 \%$ to $30 \%$, and placebo from $16 \%$ to $21 \%$. Discontinuation rates were lower in the study reported by Boyer et $\mathrm{al}^{34}$ with an overall rate of $10.3 \%$ : $10.2 \%$ for the DVS $50 \mathrm{mg}$ /day group; $12.7 \%$ for the DVS $100 \mathrm{mg}$ /day group and $8.1 \%$ for placebo discontinuation. The number of completers in the DVS group (72\%) was lower than in either venlafaxine ER group (75-150 mg/day: 85\%; 150-225 mg/day: 77\%) or placebo $(86 \%)$ in the pooled analysis. ${ }^{36}$

Nausea was the most common reason cited for discontinuation among DVS patients in all studies, except for one study with DVS $200 \mathrm{mg}$ (flexible dose) ${ }^{33}$ where insomnia (3\%) was the most frequent reason for discontinuation.

\section{Discontinuation emergent symptoms}

The impact of rapid discontinuation of DVS was also evaluated in several trials. ${ }^{32,34,35}$ Using the Discontinuation Emergent Signs and Symptoms (DESS) checklist ${ }^{45}$ to assess symptoms that first occurred or worsened during the taper period. Only a minority of patients (87) entered the abrupt taper analysis in the DeMartinis et $\mathrm{al}^{32}$ study because most patients entered the open label extension trial. The most frequent discontinuation emergent events following DVS were nausea (6\%), abnormal dreams $(5 \%)$, and infection $(5 \%)$ compared to headache $(9 \%)$ and anxiety $(9 \%)$ in the placebo discontinuation group. Following discontinuation from low-dose DVS 50 and 100 $\mathrm{mg}$ /day, the most common ( $\geq 5 \%$ ) taper emergent events were: dizziness, nausea, headache, irritability, abnormal dreams, insomnia, and diarrhea, with a reported increase $(+2.1, \mathrm{p}=0.001)$ in mean DESS scores for DVS $50 \mathrm{mg} /$ day arm compared to placebo arm (0.2) at the end of week one of the taper period. ${ }^{35}$ In the other low-dose trial, DESS scores were analyzed at 1, 2 and 3 weeks after treatment.

Table I Adverse events across studies (\%)

\begin{tabular}{|c|c|c|c|c|c|}
\hline & Placebo $^{31,32,33,34,35}$ & $50 \mathrm{mg}^{34,35}$ & $100 \mathrm{mg}^{32,34,35}$ & $200 \mathrm{mg}^{31,32,33}$ & $400 \mathrm{mg}^{31,32}$ \\
\hline Nausea & $8-11$ & $17-27$ & $16-35$ & $30-46$ & $4 I-50$ \\
\hline Dizziness & $2-12$ & $10-17$ & $7-17$ & $15-16$ & $14-19$ \\
\hline Dry mouth & $4-12$ & 10 & $16-17$ & $19-26$ & $23-25$ \\
\hline Constipation & $3-6$ & $8-9$ & $5-12$ & $9-17$ & 14 \\
\hline Insomnia & $8-11$ & $8-9$ & $9-22$ & $17-18$ & 30 \\
\hline Asthenia & $3-7$ & $6-7$ & 7 & II & $10-16$ \\
\hline Anorexia & $2-3$ & 5 & $4-12$ & $12-13$ & $10-14$ \\
\hline Somnolence & $2-8$ & 5 & $13-20$ & $10-22$ & $6-26$ \\
\hline Sweating & $3-7$ & $5-6$ & 10 & $16-28$ & $21-29$ \\
\hline Sexual dysfunction & $0-5$ & - & $1.4-3$ & $2-8$ & $2-15$ \\
\hline Anxiety & $\mathrm{I}-4$ & 3 & 5 & 5 & 6 \\
\hline $\begin{array}{l}\text { Abnormal Vision (including } \\
\text { blurred vision) }\end{array}$ & $0-1$ & 5 & 3 & 6 & 2 \\
\hline Tremor & $0-1$ & - & 4 & $8-9$ & $8-10$ \\
\hline Tachycardia & 2 & - & 3 & 3 & 5 \\
\hline Taste perversion & 2 & - & $<1$ & $<\mathrm{I}$ & 5 \\
\hline Vasodilatation & 0 & - & 2 & 5 & 4 \\
\hline Yawn & 0 & - & $3-7$ & $5-7$ & 2 \\
\hline
\end{tabular}


Results were significantly higher for DVS $50 \mathrm{mg}(\mathrm{p}=0.001)$ than placebo only after 1 week, and higher for DVS $100 \mathrm{mg}$ ( $p=0.017$ ) only during week two, when patients switched from receiving $50 \mathrm{mg}$ of DVS to no active treatment. ${ }^{34}$

One death was reported throughout the clinical trials program during the treatment period: a patient who was prescribed DVS100 mg/day committed suicide on day five of the study, although it is not known if the patient took any of the medication that was dispensed at the baseline visit. ${ }^{32}$ Two suicide attempts were reported, one in a patient taking DVS $100 \mathrm{mg} / \mathrm{day},{ }^{35}$ and another in a patient taking $400 \mathrm{mg} /$ day. ${ }^{32}$ One unintended pregnancy was also reported, without follow up information..$^{33}$

\section{Laboratory tests, vital signs, weight and ECG}

Laboratory test results showed statistically significant differences from baseline to the FOT evaluation in all the published trials, as well as significant differences versus placebo. These results included decreased bilirubin and increased gamma glutamyl transferase (GGT), alkaline phosphatase (ALP), aspartate aminotransferase (AST), and alanine aminotransferase (ALT). There were also increases in total cholesterol, high-density lipoprotein (HDL) and low-density lipoprotein (LDL) cholesterol and triglycerides.

In the high dose DVS trials (100-400 mg/day), 4 DVS patients had clinically significant laboratory findings in one study: 1 patient from the DVS $100 \mathrm{mg}$ group had a clinically significant ALT elevation ( $\geq 3$ times upper limit of normal), 1 in the DVS $200 \mathrm{mg}$ group had increased fasting glucose ( $\geq 11.10 \mathrm{mmol} / \mathrm{L}$ ), 1 in the DVS $400 \mathrm{mg}$ group had increased total cholesterol (increase $\geq 1.29 \mathrm{mmol} / \mathrm{L}$ ) and LDL cholesterol (increase $\geq 1.29 \mathrm{mmol} / \mathrm{L}$ ) and 1 patient from the same group had increased ALT, AST and ALP ( $\geq 3$ times upper limit of normal) and GGT. ${ }^{32}$ In another study with DVS 100 to $200 \mathrm{mg} /$ day, liver enzymes were significantly elevated compared to placebo at FOT evaluation. Three patients in the DVS treatment group in Septien-Velez et al $(2007)^{31}$ study had clinically significant increases in laboratory measures: 1 patient, receiving DVS $200 \mathrm{mg} /$ day, had increased AST and ALT; 1 patient in the same group had increased cholesterol; and 1 patient receiving $400 \mathrm{mg}$ /day had increased cholesterol, triglycerides and AST.

In a third study, clinically important changes in laboratory tests were reported for 3 patients taking DVS $50 \mathrm{mg}:{ }^{35}$ 1 subject had increased fasting glucose, 1 had increased total cholesterol, and 1 had elevated ALT/SGPT.
Mean decreases in weight for DVS treatment groups were statistically significant compared with baseline and placebo in both high and low dose trials. ${ }^{31-36}$ In the DVS $400 \mathrm{mg}$ group, there was a statistically significant decrease in weight compared to the DVS $100 \mathrm{mg}$ and $200 \mathrm{mg}$ groups. Data pooled from 7 clinical trials, showed that treatment with DVS was associated with small mean decreases in weight in the short term $(1 \mathrm{~kg})$, which persisted up to 6 months with a small mean increase $(<1 \mathrm{~kg})$ and was comparable to placebo. ${ }^{46}$

DVS groups had a small but significant increase in mean systolic and diastolic blood pressure and a small but significant increase from baseline in mean pulse rate. In one low dose trial, ${ }^{34} 14$ patients in the DVS group had clinically important changes in blood pressure: three patients in the DVS $50 \mathrm{mg} /$ day arm, and 3 from the DVS $100 \mathrm{mg} /$ day arm had sustained hypertension. To date, no data on exposure to DVS by patients with pre-existing hypertension have been reported.

Although a statistically significant increase in QT and QTc interval for DVS treatment groups has been reported (exception Liebowit $^{33}$ ) that seems to be dose related, no patients had ECG abnormalites considered clinically relevant.

\section{Summary and Conclusions}

At this stage in the life of DVS, it is difficult to evaluate its role over the next decade in the treatment of MDD. As with other SNRIs, the drug should be prescribed once a day. In the United States where the drug is available, the recommended dose is $50 \mathrm{mg}$ daily and dose escalation above $100 \mathrm{mg}$ is not recommended. The cost is approximately $\$ 130$ monthly for 30 tablets (50 or $100 \mathrm{mg}$ ), which compares to US $\$ 100$ monthly for duloxetine $60 \mathrm{mg} \times 30$ days and US $\$ 145$ monthly for venlafaxine XR $150 \mathrm{mg} \times 30$ days. Initially, the clinical trial program focused on doses between 100 to $400 \mathrm{mg}$ daily and these trials have been previously reviewed. ${ }^{47-50}$ Subsequently, attention has shifted to trials in the 50 to $100 \mathrm{mg}$ dose range. In the two published short-term clinical trials comparing daily doses of DVS 50 and $100 \mathrm{mg}$ for the treatment of MDD, results are inconsistent. Response rates for DVS $50 \mathrm{mg} /$ day (54\%-65\%) and for $100 \mathrm{mg} /$ day (51\%-63\%) were statistically superior to placebo in one trial, ${ }^{34}$ while $50 \mathrm{mg}$, but not $100 \mathrm{mg}$ was superior to placebo in the second trial. ${ }^{35}$ In an as yet unpublished study where venlafaxine XR and duloxetine were included as active comparators, there were no demonstrable advantages for DVS.

The advantage for DVS in the 50 to $100 \mathrm{mg}$ dose range lies mostly in the side effect profile. As shown in Table 1, there is a general trend towards increased side effect prevalence with increasing dose. Nausea is the most frequent adverse event 
across all doses but improves after 1 to 2 weeks of treatment. Cardiovascular safety was established in all reviewed trials, with only minimal increases in heart rate and blood pressure. Laboratory tests showed decrease in bilirubin levels, and increase in GGT, ALP, AST, ALT, total cholesterol, HDL, LDL, and triglycerides, demonstrating potential effects on the metabolic system. There is no evidence, however, that these effects differ from other SNRIs. There are no adverse effects on weight. In fact, treatment with DVS was associated with small mean decreases in weight in short-term trials. So far, it is unclear if discontinuation emergent effects for DVS are lower than for venlafaxine. In addition, the only relapse prevention trial evaluated DVS in the 200 to $400 \mathrm{mg}$ dose range.

Before the practicing clinician can evaluate when to prescribe DVS in the 50 to $100 \mathrm{mg}$ dose range, there is clearly a need for more published "head to head" comparisons with other SNRIs (duloxetine and venlafaxine) and with SSRIs, particularly escitalopram.

Potential advantages for DVS over other SSRIs/SNRIs drugs include the narrow dose range, where the initial dose (50 $\mathrm{mg}$ ) may prove to be the optimal therapeutic dose, in contrast to venlafaxine where extensive dose adjustments are frequently required. DVS has a direct pharmacodynamic effect, and as such has potential benefits over both venlafaxine and duloxetine. Since the drug is mainly excreted in urine and has minimal effects on the CYP450 pathway, its use in medically ill patients may be preferred over other SNRIs, although reductions in dosing are necessary in patients with significant renal impairment. The drug may also preferred in population where depression coexists with pain or vasomotor symptoms of menopause. Results from ongoing clinical trials should clarify the role of DVS in the treatment of MDD, specifically in patients from special populations.

\section{Information sources}

PubMed, PsycINFO, Ovid MEDLINE, CLCMR, CINAHL, CDSR, ACP Journal Club, DARE, CCTR, CLHTA, CLEED, clinicaltrials.gov, clinical studies.org.

\section{Disclosures}

The authors declare no conflicts of interest.

\section{References}

1. Kessler RC, Berglund P, Demler O, Jin R, Merikangas KR, Walters EE. Lifetime prevalence and age-of-onset distributions of DSM-IV disorders in the National Comorbidity Survey Replication. Arch Gen Psychiatry. 2005;62(6):593-602.

2. Murray CJ, Lopez AD. Alternative projections of mortality and disability by cause 1990-2020: Global Burden of Disease Study. Lancet. 1997;349(9064):1498-1504.
3. WHO. The global burden of disease: 2004 update. http://www.who. int/healthinfo/global_burden_disease/2004_report_update/en/index. html. Accessed December 03, 2008.

4. Lopez AD, Mathers CD, Ezzati M, Jamison DT, Murray CJ. Global and regional burden of disease and risk factors, 2001: systematic analysis of population health data. Lancet. 2006;367(9524):1747-1757.

5. Patten SB, Wang JL, Williams JV, et al. Descriptive epidemiology of major depression in Canada. Can J Psychiatry. 2006;51(2):84-90.

6. Moussavi S, Chatterji S, Verdes E, Tandon A, Patel V, Ustun B. Depression, chronic diseases, and decrements in health: results from the World Health Surveys. Lancet. 2007;370(9590):851-858.

7. Kennedy SH, Lam RW. Enhancing outcomes in the management of treatment resistant depression: a focus on atypical antipsychotics. Bipolar Disord. 2003;5 Suppl 2:36-47.

8. Trivedi MH, Rush AJ, Wisniewski SR, et al. Evaluation of outcomes with citalopram for depression using measurement-based care in STAR*D: implications for clinical practice. Am J Psychiatry. 2006;163(1):28-40.

9. Warden D, Rush AJ, Trivedi MH, Fava M, Wisniewski SR. The STAR*D Project results: a comprehensive review of findings. Curr Psychiatry Rep. 2007;9(6):449-459.

10. Thase ME, Entsuah AR, Rudolph RL. Remission rates during treatment with venlafaxine or selective serotonin reuptake inhibitors. $\mathrm{Br} J$ Psychiatry. 2001;178:234-241.

11. NemeroffCB, Entsuah R, Benattia I, Demitrack M, Sloan DM, Thase ME. Comprehensive analysis of remission (COMPARE) with venlafaxine versus SSRIs. Biol Psychiatry. 2008;63(4):424-434.

12. Weinmann S, Becker T, Koesters M. Re-evaluation of the efficacy and tolerability of venlafaxine vs SSRI: metanalysis. Psychopharmacology. 2008; 196:511-520.

13. Kennedy SH, Andersen HF, Lam RW. Efficacy of escitalopram in the treatment of major depressive disorder compared with conventional selective serotonin reuptake inhibitors and venlafaxine XR: a metaanalysis. J.Psychiatry Neurosci. 2006;31(2):122-131.

14. Thase ME. Are SNRIs More Effective than SSRIs? A review of the current state of the controversy. Psychopharmacol Bull. 2008; 41(2):58-85.

15. Thase ME, Pritchett YL, Ossanna MJ, Swindle RW, Xu J, Detke MJ. Efficacy of duloxetine and selective serotonin reuptake inhibitors: comparisons as assessed by remission rates in patients with major depressive disorder. J Clin Psychopharmacol. 2007;27(6):672-676.

16. Lam RW, Andersen HF, Wade AG. Escitalopram and duloxetine in the treatment of major depressive disorder: a pooled analysis of two trials. Int Clin Psychopharmacol. 2008;23(4):181-187.

17. Kennedy SH, Andersen HF, Thase ME. Escitalopram in the treatment of major depressive disorder: meta-analysis. Curr Med Res Opin. 2009;25:161-175.

18. Deecher DC, Alfinito PD, Leventhal L, Cosmi S, Johnston GH, Merchenthaler I, et al. Alleviation of thermoregulatory dysfunction with the new serotonin and norepinephrine reuptake inhibitor desvenlafaxine succinate in ovariectomized rodent models. Endocrinology. 2009;148(3):1376-1383.

19. Speroff L, Gass M, Constantine G, Olivier S, Study 315 Investigators. Efficacy and tolerability of desvenlafaxine succinate treatment for menopausal vasomotor symptoms: a randomized controlled trial. Obstet Gynecol. 2008;111(1):77-87.

20. Wyrwich KW, Spratt DI, Gass M, Yu H, Bobula JD. Identifying meaningful differences in vasomotor symptoms among menopausal women. Menopause. 2008;15(4):698-705.

21. ClinicalTrials.gov.Assessed October, 2008. Available from: http:// www.clinicaltrials.gov/

22. Deecher DC, Beyer CE, Johnston G, Bray J, Shah S, Abou-Gharbia M, et al. Desvenlafaxine succinate: A new serotonin and norepinephrine reuptake inhibitor. J Pharmacol Exp Ther. 2006;318(2):657-665.

23. Alfinito PD, Huselton C, Chen X, Deecher DC. Pharmacokinetic and pharmacodynamic profiles of the novel serotonin and norepinephrine reuptake inhibitor desvenlafaxine succinate in ovariectomized SpragueDawley rats. Brain Res. 2006;1098(1):71-78. 
24. Venu N, Sreekanth BR, Ram T, Devarakonda S. Desvenlafaxine succinate monohydrate. Acta Crystallogr C. 2008;64(5):0290-292.

25. Wyeth Pharmaceuticals. Pristiq ${ }^{\circledR}$ Prescribing Information. Accessed October, 2008. Available from: http://www.wyeth.com/hcp/pristiq/ prescribing-information

26. Behrle JA, Nichols AI, McGrory SB, Raible D. An open-label, randomized, single dose, dose-proportionality study of oral doses of a sustained-release formulation of desvenlafaxine succinate in healthy subjects [abstract]. Clin Pharmacol Ther. 2005;77(2):P82-P82.

27. Parks V, Patat A, Behrle J, Parker V, Decours J. Safety, pharmacokinetics (PK) and pharmacodynamics (PD) of ascending single doses of desvenlafaxine (DVS-233 SR) in healthy subjects [abstract]. Clin Pharmacol Ther. 2005;77(2):PI-75.

28. Richards LS, Behrle JA, Nichols RJ, Fruncillo JP. An ascending multiple-dose study of the safety and pharmacokinetics of a sustainedrelease formulation of desvenlafaxine succinate in healthy subjects [abstract]. Clin Pharmacol Ther. 2005;77(2):P84-P84.

29. Patroneva A, Connolly S, Fatato P, Pedersen R, Jiang Q, Paul J, et al. An Assessment of drug-drug interactions: the effect of desvenlafaxine and duloxetine on the pharmacokinetics of the CYP2D6 probe desipramine in healthy subjects. Drug Metab Dispos. 2008; $36: 2484-2491$

30. Baird-Bellaire S, Patat AA, Fauchoux N, Reh C, Nichols AI, Behrle A. Effects of chronic hepatic impairment on the pharmacokinetics and safety of desvenlafaxine succinate extended release [abstract]. Clin Pharmacol Ther. 2005;79(2):PI-73.

31. Septien-Velez L, Pitrosky B, Padmanabhan SK, Germain JM, Tourian KA. A randomized, double-blind, placebo-controlled trial of desvenlafaxine succinate in the treatment of major depressive disorder. Int Clin Psychopharmacol. 2007;22(6):338-347.

32. DeMartinis NA, Yeung PP, Entsuah R, Manley AL. A double-blind, placebo-controlled study of the efficacy and safety of desvenlafaxine succinate in the treatment of major depressive disorder. $J$ Clin Psychiatry. 2007;68(5):677-688.

33. Liebowitz MR, Yeung PP, Entsuah R. A randomized, double-blind, placebo-controlled trial of desvenlafaxine succinate in adult outpatients with major depressive disorder. J Clin Psychiatry. 2007;68(11): 1663-1672.

34. Boyer P, Montgomery S, Lepola U, Germain JM, Brisard C, Ganguly R, et al. Efficacy, safety, and tolerability of fixed-dose desvenlafaxine 50 and $100 \mathrm{mg} /$ day for major depressive disorder in a placebo-controlled trial. Int Clin Psychopharmacol. 2008;23(5):243-253.

35. Liebowitz MR, Manley AL, Padmanabhan SK, Ganguly R, Tummala R, Tourian KA. Efficacy, safety, and tolerability of desvenlafaxine $50 \mathrm{mg} /$ day and $100 \mathrm{mg} /$ day in outpatients with major depressive disorder. Curr Med Res Opin. 2008;24(7):1877-1890.

36. Lieberman DZ, Montgomery SA, Tourian KA, et al. A pooled analysis of two placebo-controlled trials of desvenlafaxine in major depressive disorder. Int Clin Psychopharmacol. 2008;23(4):188-197.
37. Feiger AD, Tourian KA, Rosas GR, et al. A placebo-controled efficacy and safety study of a flexible dose of desvenlafaxine succinate in outpatients with major depressive disorder. [Poster presentation]. Presented at the 160th Annual Meeting of the American Psychiatry Association; 19-24 May 2007; San Diego, California, USA.

38. ClinicalStudyResults.org. Accessed October 2008. Available from: http://clinicalstudyresults.org

39. Thase ME, Kornstein SG, Yeung PP, et al. Efficacy of desvenlafaxine succinate in the treatment of major depressive disorder: a pooled analysis of randomized, placebo controlled trials. [Poster presentation]. Presented at the 20th Annual USPMG Congress October 11-14, 2007; Orlando, Florida, USA.

40. Liebowitz M, Montgomery S, Boyer P et al. Evaluation of the efficacy and safety of fixed doses of desvenlafaxine succinate at $50 \mathrm{mg}$ and $100 \mathrm{mg}$ in outpatients with major depressive disorder in 2 placebocontrolled trials. [Poster presentation]. Presented at the American College of Neuropsychopharmacology Annual Meeting December 9-15, 2007; Boca Raton, Florida, USA.

41. Hamilton M. A rating scale for depression. J Neurol Neurosurg Psychiatry. 1960;23:56-62.

42. Bech P, Gram LF, Dein E, Jacobsen O, Vitger J, Bolwig TG. Quantitative rating of depressive states. Acta Psychiatr Scand. 1975;51(3):161-170.

43. Rickels K, Montgomery SA, Tourian KA, et al. A multi-center, randomized, double-blind, placebo-controlled, parallel-group study of desvenlafaxine succinate for prevention of depressive relapse in adult outpatients with major depressive disorder [poster presentation]. Presented at the 160th Annual Meeting of the American Psychiatric Association: 19-24 May 2007; San Diego, California, USA.

44. Ferguson J, Tourian KA, Rosas GR, et al. A 12-month open-label evaluation of long term safety and efficacy of desvenlafaxine succinate in outpatients with major depressive disorder [poster presentation]. Presented at: The 160th Annual Meeting of the American Psychiatric Association;19-24 May 2007;San Diego, California, USA.

45. Rosenbaum JF, Fava M, Hoog SL, Ascroft RC, Krebs WB. Selective serotonin reuptake inhibitor discontinuation syndrome: a randomized clinical trial. Biol Psychiatry. 1998;44(2):77-87.

46. Patroneva A, Zitek B, Ninan PT, et al. Analysis of weight change with short and longer term treatment with desvenlafaxine for major depressive disorder. [Poster presentation]. Presented at the 20th Annual USPMG Congress October 11-14, 2007; Orlando, Florida.

47. Kamath J, DeMartinis N, Handratta V. Efficacy and safety of desvenlafaxine succinate in the treatment of major depressive disorder. Future Neurol. 2007;2(4):361.

48. Lohoff FW, Rickels K. Desvenlafaxine succinate for the treatment of major depressive disorder. Expert Opin Pharmacother. 2008;9(12):2129-2136.

49. Sopko Jr MA, Ehret MJ, Grgas M. Desvenlafaxine: Another "me too" drug? (October) (CE). Ann Pharmacother. 2008;42:1439-1446.

50. Sproule BA, Hazra M, Pollock BG. Desvenlafaxine succinate for major depressive disorder. Drugs Today (Barc). 2008;44(7):475-487. 